University of Northern lowa

UNI ScholarWorks

Graduate Research Papers

Student Work

2007

\title{
Attention-deficit/Hyperactivity disorder in children
}

Jessica A. Weber

University of Northern lowa

Let us know how access to this document benefits you

Copyright (C2007 Jessica A. Weber

Follow this and additional works at: https://scholarworks.uni.edu/grp

Part of the Education Commons

\section{Recommended Citation}

Weber, Jessica A., "Attention-deficit/Hyperactivity disorder in children" (2007). Graduate Research Papers. 1692.

https://scholarworks.uni.edu/grp/1692

This Open Access Graduate Research Paper is brought to you for free and open access by the Student Work at UNI ScholarWorks. It has been accepted for inclusion in Graduate Research Papers by an authorized administrator of UNI ScholarWorks. For more information, please contact scholarworks@uni.edu. 


\title{
Attention-deficit/Hyperactivity disorder in children
}

\author{
Abstract \\ In the past ten years, many people have become aware of Attention Deficit Hyperactivity Disorder (ADHD). \\ This sudden increase in awareness has been good, since more children with ADHD are now being \\ properly diagnosed and treated. Furthermore, classroom teachers and parents are beginning to \\ understand this disorder and how to manage it. Fewer parents feel the issues their children are having are \\ their fault because they did not have a "good" parenting style (Phelan, 2000). The purpose of this paper is \\ to continue to increase awareness about ADHD, the effects it has on children, and the treatments and \\ interventions used to maintain or control the symptoms of the disorder. This will be accomplished \\ through an overview of the definition, symptoms, prevalence, treatment, and interventions relative to \\ ADHD.
}




\author{
A Research Paper \\ Presented to \\ The Department of Educational Leadership, Counseling, \\ and Postsecondary Education \\ University of Northern Iowa
}

\author{
In Partial Fulfillment \\ of the Requirements for the Degree \\ Master of Arts in Education
}

\author{
by \\ Jessica Weber
}

August 2007 
This Research Paper by: Jessica A. Weber

Entitled: ATTENTION-DEFICIT/HYPERACTIVITY DISORDER IN CHILDREN

has been approved as meeting the research paper requirements for the Degree of Master of Arts in Education.

\section{Darcie Davis}

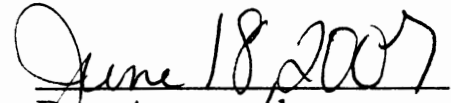

Date Approved

Greme 18,2007

Date Received
Michael D. Waggoner

Head, Department of Educational Leadership,

Counseling, and Postsecondary Education

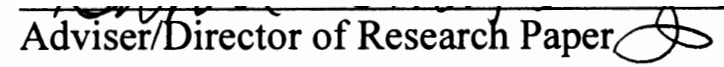




\begin{abstract}
In the past ten years, many people have become aware of Attention Deficit Hyperactivity Disorder (ADHD). This sudden increase in awareness has been good, since more children with ADHD are now being properly diagnosed and treated. Furthermore, classroom teachers and parents are beginning to understand this disorder and how to manage it. Fewer parents feel the issues their children are having are their fault because they did not have a "good" parenting style (Phelan, 2000). The purpose of this paper is to continue to increase awareness about ADHD, the effects it has on children, and the treatments and interventions used to maintain or control the symptoms of the disorder. This will be accomplished through an overview of the definition, symptoms, prevalence, treatment, and interventions relative to ADHD.
\end{abstract}


Attention-Deficit/Hyperactivity Disorder in Children

The Story of Fidgety Philip

"Let me see if Philip can

$\mathrm{Be}$ a little gentleman;

Let me see if he is able

To sit still for once at table:"

Thus Papa bade Phil behave; And Mamma looked very grave.

But fidgety Phil,

He won't sit still;

He wriggles,

And giggles,

And then, I declare,

Swings backwards and forwards,

And tilts up his chair,

Just like any rocking-horse-

"Philip! I am getting cross"

See the naughty, restless child

Growing still more rude and wild,

Written by Heinrich Hoffman, as cited in Carroll (n.d.)

The poem of "Fidgety Philip" was written in 1904 by Dr. Heinrich Hoffman who is believed to be the first person to describe the disorder that is currently called AttentionDeficit/Hyperactivity Disorder (ADHD) (Hallowell \& Ratey, 1994). This poem reinforces the idea that ADHD is not something new; it was described many years ago. However, it has only been since the 1980's that this disorder has been recognized by members of the general public who are not doctors or parents of individuals diagnosed with ADHD (Phelan, 2000). Today, it is estimated that four million children in the United States have ADHD (Wender, 2000). However, according to the American Psychiatric Association (2000), only 3-7\% of school-age children in the United States have actually been diagnosed with the disorder.

As a result of this new awareness, there is a better understanding of treatments and the causes of ADHD (Wender, 2000). Currently, it is one of the most studied psychological 
disorders in children (Loughy \& Rosenthal, 2002), and is the most commonly diagnosed behavioral disorder in childhood (Surgeon General, n.d.). In order to provide more awareness on this disorder, the following paper will begin by defining ADHD using the diagnostic criteria and subtypes of this disorder. Next, the prevalence of ADHD will be described using statistics. Following discussion of the prevalence of ADHD, the symptoms will be explained using the primary symptoms and developmental stages of the disorder. The effects of ADHD on children will then be explained through school-related problems and social problems. After that, the comorbidity of ADHD with oppositional defiant and anxiety disorders will be explained. Finally, a variety of treatments and interventions for $\mathrm{ADHD}$ will be described.

\section{Definition}

\section{Diagnostic Criteria}

According to the Diagnostic and Statistical Manual of Mental Disorders (American Psychiatric Association, 2000), in order for an individual to be diagnosed with ADHD he or she must display symptoms of inattention and/or hyperactivity-impulsivity that are more severe and occur more often than individuals at similar developmental levels. Some of these symptoms must be evident before the individual is seven years old, even though many individuals are not diagnosed until they have had symptoms for many years. Also, he or she must experience problems directly related to the symptoms in more than one setting such as home and school. It also must be demonstrated he or she has problems performing socially, academically, and occupationally in comparison with others at a similar level of development. Finally, "the symptoms associated with ADHD may not exclusively occur during the course of a Pervasive Developmental Disorder, 
Schizophrenia, or other Psychotic Disorder and are not better accounted for by another mental disorder" (American Psychiatric Association, 2000, p.85).

\section{Three Subtypes}

The majority of individuals diagnosed with ADHD usually have symptoms of inattention and hyperactivity-impulsivity, which will be described in detail later in this paper. However, some individuals may only experience symptoms of inattention or symptoms of hyperactivity-impulsivity (American Psychiatric Association, 2000). Therefore, in order for professionals to have the same understanding when they identify and communicate among each other about individuals with ADHD, individuals need to be diagnosed using the category specifying the symptoms they have displayed for the past 6 months (Loughy \& Rosenthal, 2002; American Psychiatric Association, 2000). There are currently three categories: Combined Type (ADHD-C), Predominantly Inattentive Type (ADHD-1), and Predominantly Hyperactive-Impulsive Type (ADHDHI). In order to be diagnosed with Combined Type, an individual must exhibit at least six symptoms of inattention and at least six symptoms of hyperactivity-impulsivity for six months or more. In order to be diagnosed with Predominantly Inattentive Type, an individual must exhibit at least six symptoms of inattention and less than six symptoms of hyperactivity-impulsivity for six months or more. Finally, in order to be diagnosed with Predominantly Hyperactive-Impulsive Type, an individual must exhibit at least six symptoms of hyperactivity-impulsivity and less than six symptoms of inattention for six months or more (American Psychiatric Association, 2000). 


\section{Prevalence}

ADHD is the behavioral disorder that is diagnosed most often in childhood (National Institutes of Health, 2000). Approximately 2 million (Barkley, 2000) or 3-7\% of schoolage children have been diagnosed with it (American Psychiatric Association, 2000). This means that approximately 1 or 2 children in every classroom in the United States have this disorder (Barkley, 2000).

\section{Symptoms}

\section{Primary Symptoms}

The three main symptoms that are associated with ADHD are inattention, hyperactivity, and impulsivity (Loughy \& Rosenthal, 2002). According to the Diagnostic and Statistical Manual of Mental Disorders Text Revision (DSM-IV-TR), it is considered symptomatic and/or characteristic of inattention when individuals: (a) are easily distracted by people or objects; (b) appear not to listen when spoken to; (c) have difficulty paying attention during activities; (d) forget things in daily activities; (e) do not complete instructions or homework, chores, or duties at work; (f) avoid, do not like, or do not participate in activities involving continuously using the mind; (g) do not pay attention to details and make a lot of mistakes; (h) lose things that are needed to participate in or complete tasks or activities; and (i) have a difficult time getting and staying organized. The characteristics and symptoms of hyperactivity are displayed by individuals who: (a) frequently leave their seat in the classroom or in other situations when they are expected to be seated; (b) run around or climb in situations when they are expected to be seated; (c) play with hands and feet or wiggle in their seat; (d) talk a lot; (e) constantly move; and (f) have a hard time playing or participating quietly during 
activities. The characteristics and symptoms of impulsivity are displayed by individuals who: (a) interrupt or interfere with others; (b) shout out answers before a question has been asked; and (c) have a hard time waiting for their turn in games and activities.

\section{Developmental Stages}

The symptoms of ADHD may not present themselves in the same way from day to day, week to week, or month to month. This means they may change with age. Some symptoms may become more of a problem at one age than they were at another age or vice versa, according to Loughy and Rosenthal (2002). This is because the environments children are in and the expectations placed on them vary with age (Rief, 2005). For example, in preschool, children are allowed to engage in a lot of free play, therefore, the symptoms of hyperactivity may not be as much of a problem as they are in second grade when children are expected to stay seated for long periods of time.

Preschool. It may be hard to determine what developmentally appropriate behavior is at this age and what is abnormal due to the fact that many children at this age display symptoms of inattention, hyperactivity, and impulsivity. However, children with ADHD display these symptoms more frequently and excessively in comparison to other four and five year olds and these symptoms cause impairment at home and school (Rief, 2005; American Psychiatric Association, 2000). Children who have been diagnosed with $\mathrm{ADHD}$ at this age are restless, disobedient, and aggressive. They frequently physically harm other children, do not share, and are unable to play cooperatively with others (Barkley, 2000; Loughy \& Rosenthal, 2002). They also frequently demand the attention of their parents (Barkley, 2000). 
activities. The characteristics and symptoms of impulsivity are displayed by individuals who: (a) interrupt or interfere with others; (b) shout out answers before a question has been asked; and (c) have a hard time waiting for their turn in games and activities.

\section{Developmental Stages}

The symptoms of ADHD may not present themselves in the same way from day to day, week to week, or month to month. This means they may change with age. Some symptoms may become more of a problem at one age than they were at another age or vice versa, according to Loughy and Rosenthal (2002). This is because the environments children are in and the expectations placed on them vary with age (Rief, 2005). For example, in preschool, children are allowed to engage in a lot of free play, therefore, the symptoms of hyperactivity may not be as much of a problem as they are in second grade when children are expected to stay seated for long periods of time.

Preschool. It may be hard to determine what developmentally appropriate behavior is at this age and what is abnormal due to the fact that many children at this age display symptoms of inattention, hyperactivity, and impulsivity. However, children with ADHD display these symptoms more frequently and excessively in comparison to other four and five year olds and these symptoms cause impairment at home and school (Rief, 2005; American Psychiatric Association, 2000). Children who have been diagnosed with $\mathrm{ADHD}$ at this age are restless, disobedient, and aggressive. They frequently physically harm other children, do not share, and are unable to play cooperatively with others (Barkley, 2000; Loughy \& Rosenthal, 2002). They also frequently demand the attention of their parents (Barkley, 2000). 
School-age. At this age, children who have been diagnosed with ADHD usually have been reported to have trouble sustaining attention. They are easily distracted and find organization difficult. They are also disruptive in the classroom, leaving their seat without permission, playing with inappropriate objects, repetitively tapping their hands or feet, and squirming in their seat, which prevents them and others from learning (DuPaul $\&$ Stoner, 2003). They will most likely encounter many new problems because as they get older, school will require more and more attentiveness, organization, planning, and independent work (Loughy \& Rosenthal, 2002). These new problems will ultimately lead to poor academic performance which will most likely cause parents to consider whether or not to retain their child a grade level in school (Dupaul \& Stoner, 2003; Barkley, 2000).

Adolescence. During adolescence, the symptoms of ADHD may change from being mostly hyperactive to being mostly impulsive. Adolescents with ADHD will blurt out answers or interrupt others. They may also be distracted easily by external stimuli as well as internal thoughts. This leads to them not paying attention to what others are saying and can cause them to forget to do many things. They will have difficulty thinking about the consequences of an action before they do it. Therefore, they will usually get in trouble with parents, teachers, and other authority figures (Loughy \& Rosenthal, 2002).

\section{Effects of ADHD on Children}

Children with ADHD often experience a variety of effects of this disorder. These effects often occur in academics in areas such as reading and writing and in social interactions (American Academy of Pediatrics, 2004). Ultimately, these academic and 
social effects can lead to children dropping out of school, a lack of peer relationships, etc. (Rief, 2005; Phelan, 2000).

\section{School-Related Problems}

Reading. According to Greenbaum \& Markel (2001), children with ADHD commonly experience reading difficulties both internal and external. The internal problems they experience include difficulty with comprehension and recall. Children with ADHD often have problems with comprehension because they are unable to use an inner voice to question themselves about what they have read. They also have problems paying attention while reading which causes them to miss words and important details.

Children with ADHD experience problems with recall because they have a poor working memory which means they have problems storing information and recalling it when they need to use it (Rief, 2005).

The external problems children with ADHD experience are often due to methods of teaching and textbooks. Strategies such as silent and speed reading that enhance comprehension and retention in children with ADHD because they allow them to visualize the object and action words that are important without focusing on abstract words that have no importance to meaning are not being taught (Free \& Parsons, 1997).

Textbooks may not be written or organized well and may be designed for students in another grade level. Also, many children in middle school do not have experience using textbooks. Therefore, they are not familiar with the structure or organization of textbooks, which makes learning from them difficult. Ultimately, all of these problems with reading, both internal and external, lead to failing or barely passing grades (Greenbaum \& Markel, 2001). 
Writing. According to, Greenbaum \& Markel (2001), most students who have problems with reading also have problems with writing because they are both based on language. The problems children with ADHD experience with written work fit into four categories: writing, spelling, and self-management. Problems with writing are common in children with ADHD because these children have difficulties with the preplanning and organizational components of the writing process. Pre-planning and organization are difficult for children with ADHD because they require the ability to think of ideas, plan what he/or she is going to write, and organize ideas. Usually children with ADHD do not know what they want to write about, how to organize their ideas, or how to choose a topic (Rief, 2003).

Spelling problems occur when children with ADHD are not attentive to visual detail; therefore, they do not notice letters or cannot recall letters, the order the letters belong in, or patterns within words (Rief, 2005). For example, a child with ADHD may frequently misspell words that must be recalled by sight and cannot be sounded out because they are unable to recall the letters.

Finally, the problems with self-management include procrastination and losing materials. This means that they put things off until the last minute and often can not remember where they put materials. In the long run, these problems with writing can lead to having written language problems as an adult (Greenbaum \& Markel, 2001).

Homework. Children with ADHD will most likely have problems with homework because they are often disorganized, forgetful, and easily distracted (Power, Karustis, \& Habboushe, 2001). It is especially hard for these children when they do not have someone to help them or have a set arrangement for completing assignments. Some of 
the problems children with ADHD experience with homework are due to the disorder with which they have been diagnosed with, which causes them to forget materials, fail to write down assignments or copy them down incorrectly, need to be continually reminded to work on homework, put things off, be easily distracted and frustrated, hurry through homework causing many mistakes, and lose completed homework.

However, some of the problems children with ADHD have with homework come from the assumptions of others. Teachers often assume that parents will be able to help their children with their homework. However, many parents do not know how to or cannot help their children with homework because many parents are working or do not have the necessary skills to help their children. Also, many parents and teachers assume that children will develop productive homework habits on their own. However, many children need to be taught strategies that will help them effectively complete their homework. Finally, many parents and teachers assume that all children have the ability to work independently, when in reality, many children cannot work independently, and just because they are able to work independently at school that does not mean they will be able to at home. As a result of these problems and the assumptions of others, homework has become the number one academic problem in schools (Greenbaum \& Markel, 2001).

\section{Social Problems}

Children with ADHD have more social problems than children who do not have ADHD. They are usually not popular with other children their age and more likely to be left out because their inattentive and impulsive behaviors disrupt the way they behave in social situations (Stormont, 2001). Children with ADHD have problems with self- 
control, which makes it hard for them to play games that involve following rules. They also have a low frustration tolerance, which causes everything to seem extremely important. They are also very competitive, so they often try to create or modify rules to win. When playing with others, children with ADHD often try to boss them around and are aggressive. They have trouble sharing and pay little attention to what other children want. In group situations, children with ADHD often get excited, causing them to be hyper and act strangely. Due to their difficulty interpreting social cues, they do not realize how poorly others may view them in these situations. As a result of these social problems, children with ADHD usually end up being isolated from their peers (Phelan, 2000).

\section{Comorbidity}

It is possible that in addition to ADHD, a child may have some other disorders. There is a high rate of comorbidity with ADHD (Rief, 2005), which means that two different disorders may be present in one child (Pliszka, Carlson, \& Swanson, 1999). In fact, approximately two-thirds of children with ADHD currently have or will develop at least one other disorder (Pierce, 2003). However, it is important to consider that some of this comorbidity may be the result of misdiagnosis due to the overlap in symptoms for two different disorders. Therefore, it is imperative to make sure the symptoms for diagnosing both disorders are present (Pliszka, Carlson, \& Swanson, 1999).

Oppositional defiant disorder. The aggression problems that occur most often with ADHD are defiance or noncompliance with the commands of persons in authority, poor temper control, argumentativeness, and verbal hostility, all of which fit into the psychiatric category of Oppositional Defiant Disorder (ODD) (American Psychiatric 
Association, 2000). Therefore, it is not a shock that the most common codiagnosis with ADHD is oppositional defiant disorder. In fact, approximately $40 \%$ of children with ADHD and $65 \%$ of teenagers with ADHD display behaviors associated with ODD (Jensen, Martin, \& Cantwell, 1997).

Anxiety disorder. Children with ADHD may also have high anxiety (Loughy \& Rosenthal, 2002). In fact, approximately $30 \%$ of children with ADHD have an anxiety disorder (Greenbaum \& Markel, 2001). These children may become anxious about many things that vary from test taking to staying overnight with a friend. They will be focused on a thought or fear, which may lead to the avoidance of activities and increased anxiety (Loughy \& Rosenthal, 2002).

\section{Treatment}

Many children with ADHD can be helped by treatment with medication, and many doctors, teachers, and parents view it as the solution to behavior problems (Loughy \& Rosenthal, 2002). However, for many children this is not the only intervention that is required or needed (Wender, 2000). Research implies the use of medication and behavior management programs is the best way to reduce behavior problems (Loughy \& Rosenthal, 2002). In fact, children can usually be helped the most by a combination of medication, structure in their environment, behavior management plans for home and school, accommodations at school, and some type of counseling (Rief, 2003).

\section{Medication}

Stimulant medications. The psychostimulant medications are most commonly used in treating ADHD and cause the central nervous system to become more alert (DuPaul \& Stoner, 2003). The most common of these are Dexedrine, Desoxyn, Ritalin, and 
Adderall. Approximately two thirds of children with ADHD have a positive reaction to one of these medications. Even though these medications are all used to treat ADHD, a child may respond better to one than to the others. When these medications are effective, they can help children calm down, pay attention, decrease temper tantrums, regulate emotions, improve school performance, and become organized (Wender, 2000).

However, along with the benefits of these medications there are also side effects. The two most common side effects associated with these medications are insomnia and decreased appetite (Haber, 2000). Children taking psychostimulant medications often experience a decreased appetite during the hours when their medication is actively working, but their appetite usually returns to normal until their next dose of medication is given. Therefore, this side effect can be managed by changing the time the medication is given. Children taking these medications during the day also experience insomnia at bedtime, but most children will fall asleep within an hour of going to bed. This side effect can be handled by changing the timing and dosage of the medication to make sure it is out of the child's system by bedtime (Loughy \& Rosenthal, 2002).

Nonstimulant medications. Antidepressants are sometimes used in the treatment of ADHD (DuPaul \& Stoner, 2003). They may be used along with stimulants or by themselves (Loughy \& Rosenthal, 2002). These medications are slower acting and lead to behavioral effects similar to stimulants, such as reducing the symptoms of hyperactivity and impulsivity. They may be especially helpful for treating symptoms in children who have not responded to or cannot handle the side effects of stimulants (Rief, 2003; Dupaul \& Stoner, 2003). 
Like the psychostimulant medications, antidepressants also have side effects. The side effects most commonly experienced by children on these medications are a slower heart rate and seizures. Antidepressants may slow down the electrical signal to the heart, causing problems with heart beat and heart rhythm. Therefore, children with preexisting heart conditions or a family history of heart problems should never be placed on these medications. These medications may also cause seizures. Children who have a history of seizures, have had a serious head injury, or have any other neurological problem should not take these medications because they are at an increased risk of experiencing seizures or convulsions (Barkley, 2000).

\section{Alternative Therapy}

Diet therapy. Salicylates are chemicals that decrease pain, fever, and inflammation. They are found in fruits such as apples and apricots, two vegetables (tomatoes and cucumbers), cereals, lunch meats, soft drinks, mustard, etc. When some children consume foods containing these salicylates and dyes they become hyperactive because they have abnormal reactions to these substances. Therefore, removing these substances from a child's diet may change his/her behavior (Haber, 2000). However, only about $10 \%$ of children with ADHD actually have abnormal reactions to these substances, so this therapy will only benefit a small number of children (American Academy of Pediatrics, 2004).

Megavitamin therapy. Megavitamin Therapy is sometimes used instead of traditional therapies. Supporters of this treatment believe the bodies of children with ADHD use materials differently than the bodies of children who do not have the disorder. These supporters believe that taking a variety of vitamins, minerals, and amino acids can treat 
these differences (Haber, 2000). However, this belief is not backed by research. In fact, many children given this treatment may experience negative side effects due to the way their livers function while taking large amounts of vitamins (American Academy of Pediatrics, 2004).

Biofeedback. Biofeedback is another method used in the treatment of ADHD. It is usually used with children who have not responded well to medication or whose parents choose not to medicate them (Haber, 2000). In this treatment, a child is attached to a machine that measures physiological responses to stressful conditions, as well as, stressreduction methods. The measurements received from the machine allow a trained therapist to determine whether or not a child is more or less stressed in certain conditions. They also allow the therapist to determine which stress-reduction methods work the best for the child. The goal is to use the information received to help the child learn to recognize his or her bodily reactions to stressful conditions and how to best control them (Freed \& Parsons, 1997). Unfortunately, this treatment has not accomplished this goal and many clinics using this treatment have closed down (Freed \& Parsons, 1997).

Herbal treatments. Herbal therapy is usually used by parents who view herbs as natural substances that have not been altered in any way. These substances are thought of as safe in comparison with pharmaceutical drugs which are created in laboratories (Haber, 2000; Loughy \& Rosenthal, 2002). The herbs used most often in the treatment of ADHD are St. John's wort, ginkgo biloboa, and kava-kava (Haber, 2000). Unfortunately, these substances may not be safe and are not regulated by the Federal Drug Administration. Therefore, these substances have not be adequately tested which means 
they could have many negative side effects of which individuals are not aware. (Loughy \& Rosenthal, 2002; Haber, 2000).

\section{Interventions}

As stated earlier, children can be helped most by a combination of treatments and interventions (Rief, 2003). Therefore, several different interventions are needed to positively impact behavior (Barkley, 1998). These interventions may include one or more of the following: behavior management, social skills training, and/or behavioral family therapy (DuPaul \& Stoner, 2003).

\section{Behavior Management}

Token reinforcement programs. Token programs use items such as stickers to give instant reinforcement for desired behaviors. When a child earns a preset amount of these items (tokens), they may be exchanged for an activity, privilege, treat, or toy. It is hard for children with ADHD to be patient; therefore, the immediate reward of a token helps these children stay motivated to keep working on their goals (Rief, 2005).

Contracts. The contract is usually an agreement between a child and an adult describing the role each of them will play in reaching a behavioral goal. It is made to specifically meet the needs of the child who is having behavioral difficulties. The child and the adult work together to identify and pick one or more behaviors the child agrees to try to improve. The adult and the child then agree on the reward that will occur when the child meets the goal by improving the behavior(s). They may also include a negative consequence that will occur if the child fails to reach their goal. Finally, both the adult and the child sign the contract to show they both agree to its terms (Rief, 2005). 
Response cost. In response cost, a child is given a certain amount of tokens at the beginning of the day. The number of tokens given should be fewer than the number of times the child usually displays the targeted behavior during the day. Throughout the day, if the child displays the targeted behavior, a token will be taken away. If there are any tokens left at the end of the day, the child is given a preset reward. Once the targeted behavior begins to be reduced, the number of tokens given at the beginning of each day is also reduced. This continues until the targeted behavior is at a level that can be managed (Rief, 2005).

Self-monitoring. In self-monitoring, a child is trained how to observe specific parts of his or her behavior and/or academic performance (Parker, 2002). An audio or visual stimulus such as a beep from a tape recorder is typically used to signal the child to observe his or her behavior. The child then records his or her observations (DuPaul \& Stoner, 2003) on an index card or piece of paper that is at his or her desk (Parker, 2002).

\section{Training}

Social skills training. As discussed earlier, children with ADHD often have trouble getting along with others and maintaining friendships since their problems with inattention and impassivity disrupt the way they interact with others. Therefore, interventions designed to address these social problems should be put into practice in order to prevent even more social problems. In social skills training, a child learns about proper social skills. This training includes learning about things such as conversation skills, joining peer activities, playing cooperatively, dealing with anger, maintaining selfcontrol, and solving arguments. After the training is completed, the child attends follow- 
up sessions to help maintain the skills he or she learned in the training (Sheridan, Dee, Morgan, Mcconzlick, \& Walker, 1996).

Parent training. In parent training, parents of children with ADHD are given instruction about behavior management strategies that will improve their child's attention at home. The focus of the training is usually on helping parents supervise the completion of academic work such as homework. The training may be conducted in a school by a school psychologist, social worker, or counselor or it may be conducted in the community by a trained professional (Webster-Stratton, 1994). The training usually lasts nine weeks. Topics include things such as why children display disruptive behaviors, methods to increase independent play, development of token reinforcement programs, use of response cost from positive reinforcement, strategies to manage child's behavior, and how to handle behavior problems in the future. After the training is completed, parents attend follow-up sessions for several months to help maintain the skills and strategies they learned (DuPaul \& Stoner, 2003).

Therapy

Behavioral family therapy. In Behavioral Family Therapy, medication or management strategies are combined with a form of family therapy to address problems between parents and their adolescent children. The therapy involves skill-building techniques such as instruction on ways to problem solve and methods of communication. In many cases, cognitive therapy techniques are used to change the irrational beliefs in the family (Robin \& Foster, 2003). 
ADHD in Children 18

Conclusion

ADHD is a disorder affecting the lives of many children. Therefore, increased awareness of this disorder is needed. In order to increase awareness of this disorder, this paper defined ADHD using diagnostic criteria and subtypes of this disorder. Then, the prevalence of this disorder was discussed through statistics. Next, symptoms of this disorder were explained. Following the explanation of the symptoms of ADHD, the effects of this disorder on children were described through school-related and social problems. After that, the comorbidity of ADHD with Oppositional Defiant Disorder and Anxiety Disorder was discussed. Finally, a variety of treatment methods and interventions were described. Hopefully, with an increased awareness of ADHD, the disorder will continue to be treated and controlled. 


\section{References}

American Academy of Pediatrics. (2004). ADHD: A complete and authoritative guide. USA: American Academy of Pediatrics.

American Psychiatric Association. (2000). Diagnostic and statistical manual of mental disorders ( $4^{\text {th }}$ ed., revised). Washington, DC: American Psychiatric Association. Barkley, R. (2000). Taking charge of ADHD (revised). New York, NY: Guilford Press. Barkley, R. (1998). Attention-deficit hyperactivity disorder: A handbook for diagnosis and treatment $\left(2^{\text {nd }}\right.$ ed.). New York, NY: Guilford Publications, Inc.

Carroll, R. (n.d.). Classic poems for children. Retrieved November 1, 2006, from http://www.storyit.com/classics/Justpoems/fidgetphilip.htm.

Cooper, P. \& O'Regan, F. (2001). Educating children with ADHD: A teacher's manual. New York, NY: RoutledgeFalmer.

Dupaul, G. \& Stoner, G. (2003). ADHD in schools: Assessement and intervention strategies. New York, NY: Guilford Press.

Freed, J. \& Parsons, L. (1997). Right-brained children in a left-brained world:

Unlocking the potential of your add child. USA: Simon \& Schuster Adult Publishing Group

Greenbaum, J. \& Markel, G. (2001). Helping adolescents with ADHD and learning disabilities: Ready-to-use tips, techniques, and checklists for school success. USA: Center for Applied Research in Education.

Haber, J. (2000). ADHD: The great misdiagnosis. Chicago, IL: Taylor Trade Publishing. 
Hallowell, E. \& Ratey, J. (1994). The evolution of a disorder. Retrieved February 6, 2007 , from http://www.pbs.org/wgbh/pages/frontline/shows/medicating/adhd/evolution.html. Jensen, P., Martin, D., \& Cantwell, D. (1997). Comorbidity in ADHD: Implications for research, practice, and DSM-IV. Journal of the American Academy of child and Adolescent Psychiatry, 36, 1065-1079.

Loughy, R. \& Rosenthal, D. (2002). ADHD: A survival guide for parents and teachers. Duarte, CA: Hope Press.

National Institutes of Health. (2000). Consensus development conference statement: Diagnosis and treatment of attention-deficit-hyperactivity-disorder (ADHD). Journal of the American Academy of Child and Adolescent Psychiatry, 39, 182193.

Parker, H. (2002). Problem solver guide for students with ADHD. Plantation, FL: Specialty Press.

Phelan, T. (2000). All about attention deficit disorder: Symptoms, diagnosis, and treatment: Children and adults ( $2^{\text {nd }}$ ed.). Glen Ellyn, IL: Child Management, Inc. Pierce, Karen. (2003). Attention-deficit/hyperactivity disorder and comorbidity. Primary Psychiatry, 10, 69-76.

Pliszka, S., Carlson, C., \& Swanson, J. (1999). ADHD with comorbid disorders: Clinical assessment and management. New York, NY: Guilford Press.

Power, T., Karustis, J., \& Habboushe, D. (2001). Homework success for children with ADHD: A family-school intervention program. New York, NY: Guilford Press. 
Rief, S. (2005). How to reach and teach children with ADD/ADHD: Practical techniques, strategies, and interventions ( $2^{\text {nd }}$ ed.). San Francisco, CA: JosseyBass.

Rief, S. (2003). The ADHD book of lists. San Fransisco, CA: Jossey-Bass.

Robin, A. \& Foster, S. (2003). Negotiating parent-adolescent conflict: A behaviouralfamily systems approach. New York, NY: Guilford Press.

Sheridan, S., Dee, C., Morgan, J., McCormick, M., \& Walker, D. (1996). A multimethod intervention for social skills deficits in children with ADHD and their parents. School Psychology Review, 25, 57-76.

Stormont, M. (2001). Social outcomes of children with AD/HD: Contributing factors and implications for practice. Psychology in Schools, 38, 521-531.

Surgeon General. (n.d.). Attention-deficit hyperactivity disorder. Retrieved November 1,2006, from http://www.surgeongeneral.gov/library/mentalhealth/chapter3/sec4.html

Webster-Stratton, C. (1994). Advancing videotape parent training: A comparison study. Journal of Consulting and Clinical Psychology, 62, 583-593.

Wender, P. (2000). ADHD: Attention-deficit hyperactivity disorder in children and adolescents. Oxford: Oxford University Press. 